\title{
Process Oriented, Performance Headed Strategy
}

\author{
N. Acur, U. Bititci \\ CSM, DMEM, University of Strathclyde, Glasgow, UK, \\ Tel: 44-141548 2015/2254, Fax: 44-1415520557 \\ e-mail:nuran.acur@strath.ac.uk,csm@strath.ac.uk
}

\begin{abstract}
PROPHESY (Process Oriented, Performance Headed Strategy) develops a model that builds-up a detailed picture of how organisations deploy and review their strategies and objectives and turn them into plans and actions at all levels of the organisation. The model helps to capture corporate objectives, performance measures and financial information as references for future business improvement.
\end{abstract}

\section{KEYWORDS}

Strategy, Business Process, Performance Measurement

\section{INTRODUCTION}

The impact of changing markets, stakeholders' requirements and competitive pressures in the business environment is increasing. This paper proposes that a traditional approach to strategy making is no longer appropriate because of its focus on vertically based, business functions such as marketing, finance, production and so on. The paper presents an alternative approach adopting a more horizontally oriented methodology that focuses on business processes as well as operational and financial performance. This approach assumes a dynamic business environment and provides tools with which the challenges faced by the business environment may be tackled more effectively.

The proposed Process Oriented, Performance Headed Strategy (PROPHESY) builds upon earlier work conducted on Performance Measurement (Bititci et al. 1995, 1999) and Viable Structures (Beer 1985) as well as on the principle of Hoshin Planning, the EFQM Excellence Model and Balance Score Cards. The objective of PROPHESY is to make Process Based Strategy development a competitive 
weapon in identifying how fast company structures adapt to new stakeholder requirements.

PROPHESY develops a model that builds-up a detailed picture of how organisations deploy and review their strategies and objectives and turn them into plans and actions at all levels of the organisation. The model helps to capture corporate objectives, performance measures and financial information as references for future business improvement.

\section{BACKGROUND OF RESEARCH}

Manufacturing systems are complex and dynamics environments composed of a broad range of inter-related technological, organisational, cultural, social, political and commercial factors. The content of the strategy literature review should reflect this multi-faceted characteristic.

Traditionally, strategy models have depicted companies as being made-up of a functional framework. Successive models have tended to add to this depiction by linking together competitive criteria, manufacturing decision areas and performance measurement with only minor modifications to this basic theme. In this field strategy models have been developed by: Hayes and et al (1979), Platts (1996-1998), Hill (1985), Skinner (1978), Hammer (1995), Voss (1992) and so on.

The following list outlines typical, recently emerging contemporary stakeholder requirements from Preiss et al (1996):

1. Systems that can always deliver to customers' increasing expectations

2. To be able to capture and secure market position in increasingly intense, global markets

3. Improved, formal education and learning opportunities in advanced technologies

4. Segmentation of mass markets towards niche markets

5. Improved partnerships between the suppliers and customers who comprise the value-adding chain in-line with collaborative production objectives

6. Increased consideration during corporate decision making of the rising impact of changing values, such as environmental issues and job creation

Traditional functional techniques for formulating strategies normally first concentrate on identifying potential attractive markets and businesses and then looking at whether it is feasible and possible to enter them (Hammer and Champy, 1995). This approach tends not to tackle all the above issues. A more comprehensive approach would be for companies to focus on customers and value adding processes to meet their requirements and improve their efficiencies. This approach and the above emergent stakeholder requirements necessitate a compatible company structure. The structure alluded to by the above requirements call for a systems way of thinking about support and value-adding activities.

The Viable System Model (VSM) illustrates this systems approach. The VSM was developed by Stafford Beer as a guide to the organisation of business processes according to cybernetic principles (Virgen, 1998). VSM provides a powerful 
application of system theory for the strategic analysis and planning of a business (Bititci, 1999). The VSM embraces the science of cybernetics that defines the effective set of ideas to describe the ability of a system achieve homeostasis through recursive self-production (Beer 1985,Virgin1998, and Bititci 1998). Hammer and Champy (1993) look at a system's approach towards Business Processes (BP). Since then, there has been a considerable amount of research into the definition of BP architecture upon which processes and capabilities are strongly dependent (Talwar, 1997).

The CIM-OSA standard (AMICE-ESPRIT, 1989) has classified a BP architecture within the three categories of activity. The CIM-OSA standard classifies processes into "Manage, Operate and Support". The Manage Processes relate specifically to business direction and strategy as well as business planning and control. (Child et al, 1994,1995) PROPHESY approach does not emphasise the Manage Processes separately because it exists naturally within strategy development. The Operate Processes directly produce value for customers. Value is provided if activities lead directly to the fulfilment of customers' requirements.

Figure 1 shows how the VSM, Hammer and Champy and CIM-OSA approaches are combined to provide a framework for the VSM and business process thinking combination. It provides a structure for planning and managing today's dynamic organisation environment (Bititci 1995, 1998).

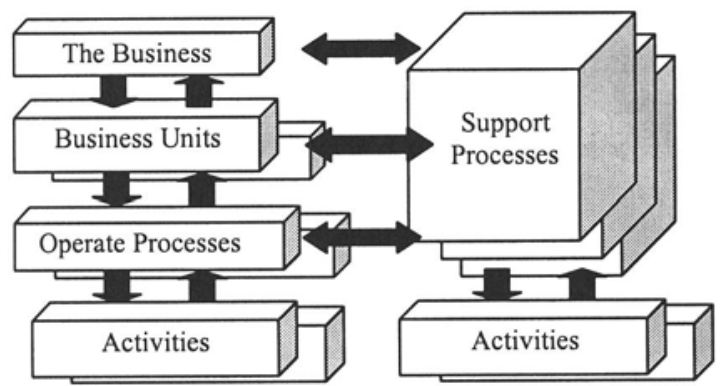

Figure1 An overview of the Viable Business Structure

Before applying the approach it is necessary to consider the following two issues:

\subsection{Process versus Functional Approach}

After an extensive literature review of strategies, the disadvantages of a functional approach were categorised into four headings. These are illustrated in Table1.

Feurer, 1995 illustrated the disadvantages of functional approach and pointed towards the need for a system process thinking approach. A process perspective adopts a long-term perspective toward strategy development, problem solving and learning. This approach tends to provide optimal solutions across functions. A functional perspectives focuses on shorter-term solutions that are optimised for individual functions only. This approach tends to provide few opportunities for strategic learning and improvement. 
It was clear from the interviews in four British Blue Chip companies, conducted in December 98, that there was some misunderstanding of the differences between functional and process based approaches to strategy development. In general, a process-based approach adapts a top down perspective that views a whole organisation as a single proactive (purposeful) system (Flood and Jackson, 1981). The functional based approach, however, views an organisation as a set of individual departments. Each department has a tendency to regard themselves not as a part of a whole but rather as the whole.

Table 1: Disadvantages of Functional Approach

1. Structure

- Functional hierarchies generate their own self-serving tasks and complexes as managers seek to expand their influence and power (Talwar, 1997)

- Staff are relocated along the needs of a hierarchy to satisfy the targets against which the hierarchy is measured (Talwar)

- Functional Strategies aim to ensure 'high vertical' agreement. With this approach some proposals are difficult to realise without 'extremely diligent management.' (Gianesi, 1998)

2. Process

- A Company that automates its production process without understanding the impact upon other functions is laying the groundwork for a potentially acrimonious future relationship. This situation impairs its ability to compete as effectively as companies that have co-ordinated and matched more closely the changes in their product and process structure (Hayes at al., 1979)

- An indication of how a function is performing cannot always indicate its impact upon the overall performance of a complete process (Wheelwright).Functionally based accounting and control systems, therefore do not ensure a 'balanced set of measures'(Talwar,1997)

3. Customers

- Customer satisfaction and service delivery is often not a functioned priority (Talwar,1997)

- Functional orientation may not correspond with doing what is best for the customer or shareholder (Talwar, 1997)

4. Co-ordination

- Priorities between functions may differ causing possible delays as work waits for processing

- Functional structures often not only cultivate unhealthy competition but also foster conflict and barriers between parts of an organisation. (Talwar,1997)

- Decisions at different levels within functions often have their own personal objectives and agendas. Decisions and actions are typically made within the scope of individual functions.

- Hierarchical and bureaucratic functional organisations tend to favour 'non-synergetic functional objectives'. Individual functional decisions tend not to be coherent but rather may conflict and may not contribute at all to wider business and corporate objectives (Gianesi, 1998)

- A functional approach cannot co-ordinate effectively the essential elements of strategy development, such as its resources, skills, market situation, competitive pressures, and general business philosophy (Hayes at al., 1979) 


\subsection{Rethinking In A New Process Organization}

Slevin and Colvin (1990) compare functional and process based management roles and conclude that the process approach provides opportunities for more idea sharing, innovation and co-operation. It makes possible improvements to the performance of the whole organisation because of a shift in specialist knowledge to whole system knowledge.

Feurer (1995) explains the process of management that can be maintained by a number of standard tools and frameworks to ensure balance between 'efficiency' (doing things right), 'effectiveness' (doing the right things) and 'evolution' (the ability to adopt to change and sustain a competitive position).

\section{PROPHESY REQUIREMENTS}

So far, the paper has reviewed and discussed the disadvantages of a functional approach, how a transition can be managed to a process approach and how change in thinking is required within the VSM.

This section states research requirements. It compares existing process approaches with PROPHESY. The objectives and benefits of the research are described. Strategic success requirements can be classified into the following four parts:

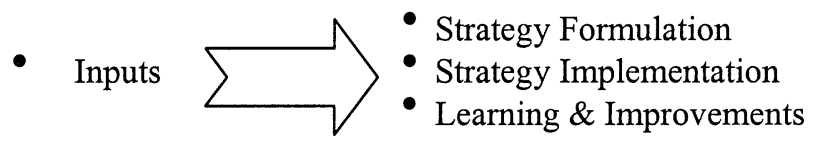

Table 3 compares three commonly known strategy development tools, namely 'Hoshin, Focus and Cambridge' with PROPHESY. The Hoshin approach focuses on daily operation strategies that are defined by describing activities and resource allocations for short-term solutions. (Cowley and Domb 1997, Feurer 1995, Brachulis 1998) The Focus approach is designed for ongoing use over a long period of time to build effective strategies and more importantly to accumulate knowledge on how to tackle the process of building effective strategy. Cambridge model is developed for managers who want to take a more strategic view of one's business to develop and sustain a competitive advantage (Platt et al 1996-1999).

In literature, most methodologies were developed specifically for the functional strategy approach. Recently, process oriented approaches have been come to the fore. These methodologies are systematic to strategy development and their ongoing development is based on hands-on experience and case studies. There are, however, a number of limitations which can be summarised as follows:

- There is a lack of systematic approach that specifically can lead a framework of standardised strategies against which an organisation can measure its performance. This standardisation allows comparisons to be made and best-inclass performance to be identified. Most existing methodologies are based 
solely on either profit and loss accounts without paying attention to the impact on a company's performance and integrating the strategy into performance.

- There is a need for an integrated holistic and objective view of the organisation. Most methodologies concentrate on organisational processes without paying sufficient attention to the roles and responsibilities of the stakeholders that carry out the activities and comprise these processes.

- There is a lack of integrated tool sets that allow modelling, business analysis, and self-assessment using EFQM for ongoing learning and improvement.

- Most methodologies fail to recognise the importance of industry classification at the beginning of the integration of IT to the scenario planning.

Table 3 Comparison between Existing Process Approach to PROPHESY

\section{Covered $\square$ Limited Coverage $\quad x$ Not Covered}

\section{Requirements}

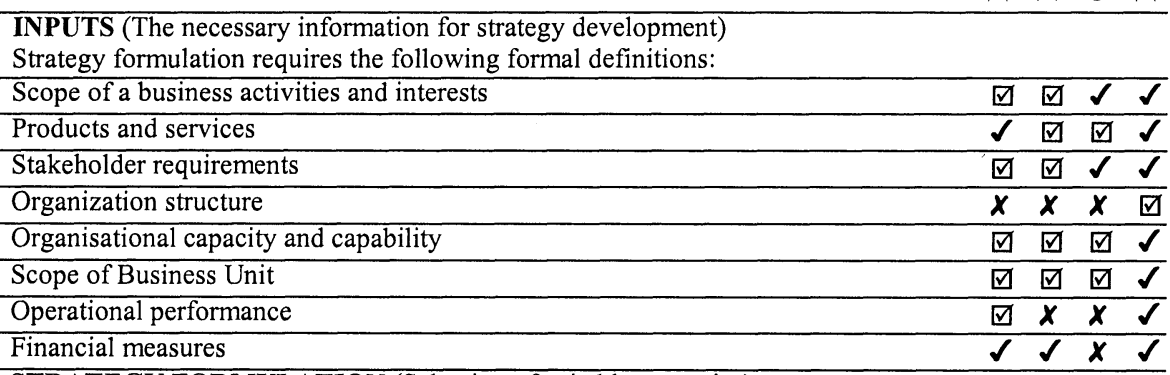

STRATEGY FORMULATION (Selection of suitable strategies)

The following are required tasks in strategy formulation:

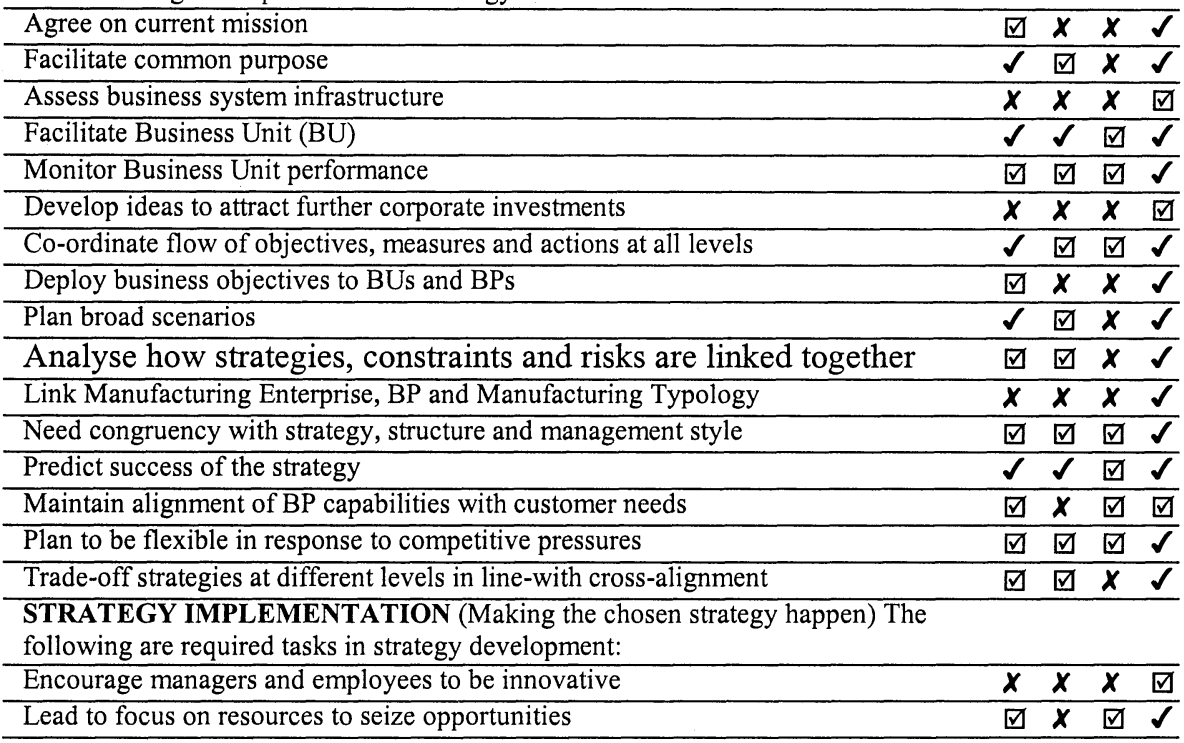




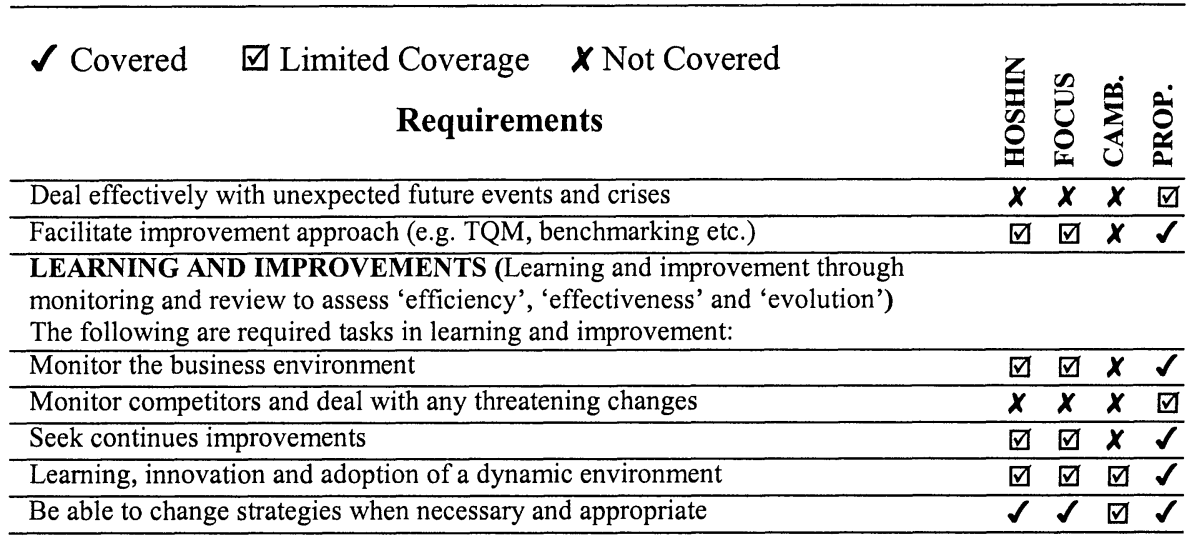

\section{PROPHESY METHODOLOGY}

The objective of PROPHESY is to propose a systematic methodology to help manufacturing companies successfully carry out strategy development. The approach to strategy development emphasises the importance of operational performance and financial issues. Organisations are described in terms of Business Units (BU) and Business Processes (BP). Manufacturing and Business Strategies are integrated within each Business Unit for all Business Processes.

PROPHESY's proposed approach to strategy development is unique for the following reasons:

- Corporate objectives and business performance drive strategies for each BU

- Business and operational performance elements contribute to policy and strategy making

- The strategy of each BU drives strategies for its BP by linking operational performance to business performance as well as to profit and loss accounts

- The overall business strategy is then compiled as a result of consolidation and trade-off between objectives, priorities and conflicts of $\mathrm{BU}$ and their $\mathrm{BP}$

\section{CONCLUSION}

PROPHESY builts upon the deficiencies of traditional functional approach methods and extends current process based strategy development processes and approaches. The Viable Systems Model and the CIM-OSA have been used to facilitate transformations from a functional approach to a process-oriented approach.

In December 1998, detailed faces to face interviews were conducted in 4 British Blue Chip companies to validate the model. The result of these interviews are summarised as follows:

- Once the executives and managers explain differences between process and functional approach, there was an eagerness for the approach. 
- They can relate to and understand the main principles of a process approach

- They agreed that the effectiveness of their company's strategy would be improved using a process based approach within the EFQM model

It is apparent from the research that the companies would be willing to transform their strategy formulation methods from a functional to process approach. The main contributions of PROPHESY in the general field of strategy are as follows:

- It provides a theoretical basis for strategy development made up of elements from VSM, EFQM, stakeholder analysis, operational performance, financial measure, motivation theory, knowledge and IT management, benchmarking

- It emphasises a process perspective through the way it apportions an organisation into $\mathrm{BU}$, and because of the requirements for collaboration between suppliers, customers and inter-company during strategy formulation

- It views the organisation as being self-reliant at a BU and holistic at a BP level

- It is sensitive to different industries, cultures and organisational environments

- It provides a set of business analysis techniques to assist the development of

- business objectives at all levels of an organisation as common objectives

- It provides guidance to ensure successful performance results and sets up a system for continuing improvement, monitoring and controlling

- It highlights the importance of stakeholder satisfaction and self-learning from the current strategy within each business unit

BUs and BPs naturally exist and are critical to the viability of the organisation, whether the management recognises this or not. Strategies should, therefore, be focused around them. Alongside, performance measurement to indicate the effectiveness and/or efficiency of process or business components against given strategies rather than merely focuses on individual functions. The work will be done to necessitate the need for a process approach for 'dynamic environment'.

\section{REFERENCES}

AMICE-ESPRIT (1989), CIM-OSA Reference Architecture

Beer S. (1985) Diagnosing the system for organisation, Wiley, Chister, England Bititci, U.S., Carrie, A. (1998) Diagnosing Integrity of your PMS, Control, April Bititci, U., Turnover, T. (1999) The Viable Business Structure, Control, 1999 Brachulis Jim (1998) Implementing Strategic Goal Development and Other Nontraditional Roles for Industrial Engineers, IIE Solutions, 30:8 pp.25-29.

Childe, S.J., Maull R.S., and Bennett J. (1992) Frameworks for Understanding Business Process Re-engineering IJOPM, 14:12, pp.22-34. (48)

Childe, S.Jand et al (1995) The Application of Generic Process Models in BPR, Working Conference of the International Federation for Information Processing, Working Group 5.7, Ireland, pp.110-120.

Cowley M and Domb E. (1997), Beyond Strategic Vision Effective Corporate Action with Hoshin Planning, America.

Feurer R. et all (1995) Analysis of Strategy formulation and Implementation at Hewlett-Packard, Management Decision, 33:10, pp.4-16 
Flood R.L. and Jackson M.C. (1991) Creative Problem Solving. Total Systems Intervention, John Wiley and Sons Ltd.

Gianesi I.G. (1998) Implementing Manufacturing Strategy through Strategic Production Planning, IJOPM, 18:3, pp.286-299.

Hayes H. Robert, and Wheelwright G. Steven (1979) The Dynamics of ProcessProduct Life Cycles, Harvard Business Review, March-April, pp.126-136.

Kenneth P. (1996) Co-operate to compete building agile Bus. Relationships , Ame.

Mills J. and Neely A. et al (1998) Manufacturing Strategy: A Pictorial Presentation, IJOPM, 18: 11, pp.1067-1085.

Platts K.W. et all (1996) Evaluating Strategy Formulaion Processes, International Journal Production Economics, 46-47, pp.233-240.

Platts K.W. et al (1998) Testing Manufacturing Strategy Formulation Processes, International Journal Production Economics, 56-57, pp.517-523.

Sacket J. Peter, Maxmell J. Dauglas, Lowenthall A. Paul (1997) Customising Manufacturing Strategy, Integrated Manufacturing Systems, 8:6, pp.359-364

Slevin D.P. and Colvin J.G. (1990) Juggling Entrepreneurial Style and Organisational Structure, Sloan Management Review, 31:2, winter

Talwar R.(1997), Business re-engineering- a strategy-driven approach, Strategic Change, edited by Colin A.Carnall, Oxford, pp.102-129

Virgen R. (1998) Cybernetic and Business Processes: Using the VSM to Develop Enterprise Proc. Architecture, Knowledge and Pro. Management, 5:2, 118-131 